Article

\title{
Synthesis of polymer/CNTs composites for the heterogeneous asymmetric hydrogenation of quinolines
}

\author{
Lin Tao a,b,t, Chunzhi Li a a,b, , Yiqi Ren a,b, He Li a Jian Chen a,b, Qihua Yang a,* \\ a State Key Laboratory of Catalysis, iChEM, Dalian Institute of Chemical Physics, Chinese Academy of Sciences, Dalian 116023, Liaoning, China \\ b University of Chinese Academy of Sciences, Beijing 100049, China
}

A R T I C L E I N F

Article history:

Received 24 May 2019

Accepted 1 July 2019

Published 5 October 2019

\section{Keywords:}

Heterogeneous asymmetric

hydrogenation

Quinoline

Diamine ligand

Polymer

Carbon nanotube

\begin{abstract}
A B S T R A C T
The development of heterogeneous catalytic processes is crucial for the synthesis of chiral compounds for both academic and industrial applications. However, thus far, such achievements have remained elusive. Herein, we report the heterogeneous asymmetric hydrogenation of 2-methylquinoline over solid chiral catalysts, which were prepared by the one-pot polymerization of $(1 R, 2 R)-N$-(4-vinyl-benzenesulfonyl)-1,2-diphenylethane-1,2-diamine (VDPEN) and divinylbenzene (DVB) in the presence or absence of activated carbon (C) or carbon nanotubes (CNTs), followed by Ru coordination and anion exchange. The solid chiral catalysts were fully characterized by $\mathrm{N}_{2}$ sorption analysis, elemental analysis, TEM, FT-IR spectroscopy, and ${ }^{13} \mathrm{C}$ CP-MAS NMR. All the solid chiral catalysts could efficiently catalyze the asymmetric hydrogenation of 2-methylquinoline to afford 2-methyl-1,2,3,4-tetrahydroquinoline with $90 \%$ ee. Studies have shown that polymer/C and polymer/CNTs composites are more active than pure polymers. The polymer/CNTs composite exhibited the highest activity among all the solid chiral catalysts under identical conditions, owing to the unique morphology of CNTs. The recycling stabilities of the solid chiral catalysts were greatly improved when ionic liquids (ILs) were employed as solvents; this is mainly attributed to the decreased leaching amount of anions owing to the confinement effect of ILs on ionic compounds.
\end{abstract}

(C) 2019, Dalian Institute of Chemical Physics, Chinese Academy of Sciences. Published by Elsevier B.V. All rights reserved.

\section{Introduction}

Optically active 1,2,3,4-tetrahydroquinoline derivatives widely found in natural products are important intermediates in the production of biological medicines [1-3]. For example, 6-fluoro-2-methyl-1,2,3,4-tetrahydroquinoline is an important building block of antibacterial agent, (S)-flumequine [4]. The development of efficient methods for synthesizing chiral tetrahydroquinoline derivatives is of great importance academically and industrially. In recent years, a series of chiral Brönsted acid catalysts have been developed for the asymmetric transfer hydrogenation of quinolines with Hantzsch esters as the hydrogen source [5-7]. In terms of atom efficiency and environmental friendliness, the asymmetric hydrogenation of corresponding quinolines to tetrahydroquinolines is more desirable than the asymmetric transfer hydrogenation method. The asymmetric hydrogenation of quinolines was firstly realized by Zhou and co-workers in 2003 [8] by a substrate activation strategy using iridium-chiral bisphosphine ligand as a catalyst and iodine as an activator. Inspired by Zhou's work, great progresses have been achieved in the asymmetric hydrogenation of quinolines using phosphorus ligands based metal complexes

\footnotetext{
*Corresponding author. Tel: +86-411-84379552; Fax: +86-411-84694447; E-mail: yangqh@dicp.ac.cn

+ These authors contributed equally to this work.

This work was supported by the National Natural Science Foundation of China $(21733009,21621063)$ and the Strategic Priority Research Program of the Chinese Academy of Sciences (XDB17020200).

DOI: S1872-2067(19)63398-X | http://www.sciencedirect.com/science/journal/18722067 | Chin. J. Catal., Vol. 40, No. 10, October 2019
} 
as catalysts [9-12]. In addition to the phosphorus ligands based metal complexes, the chiral diamine ligand-based cationic metal complex, Ru/Ts-DPEN, was firstly used for the asymmetric hydrogenation of quinolines by Fan and co-workers in 2008 $[13,14]$. Chiral cationic diamine ligands based catalytic systems have the advantages of air and moisture stabilities over phosphorus ligands based catalytic systems, and they can be handled under ambient conditions.

Recycling of expensive chiral catalysts is crucial to practical applications. Fan and co-authors $[13,15]$ attempted to recycle the homogeneous catalyst, $\mathrm{Ru} / \mathrm{Ts}-\mathrm{DPEN}$, via a liquid-liquid phase separation method, in which the products were extracted by $n$-hexane and the catalyst remained in the solvent after the reaction; examples of such solvents include ionic liquids (ILs) or short-chain triethylene glycol. The complicated separation process led to the wastage of solvent and consequent increased costs. The development of homogeneous asymmetric catalysis methods has recorded great progress in the last decade; however, practical application in industry is very difficult. One of the major obstacles is the difficulty in product purification, and the separation and recycling of homogeneous chiral catalysts. Heterogeneous asymmetric catalysis methods having the advantages of easy product purification, catalyst recycling, and the possibility for continuous production of chiral compounds using a fixed bed reactor have attracted much attention from researchers over the past decades [16].

The preparation of efficient solid chiral catalysts is one of the key issues associated with heterogeneous asymmetric catalysis. The immobilization of homogeneous chiral catalysts on solid supports is a straightforward and facile method for the preparation of solid chiral catalysts [17-21]. In decades past, different types of heterogeneous asymmetric catalytic reactions have been realized using immobilized homogenous catalysts, such as asymmetric epoxidation, asymmetric transfer hydrogenation, asymmetric Michael addition reaction, and asymmetric Aldol reaction [22]. As far as we know, few studies on the asymmetric hydrogenation of quinolines over chiral solid catalysts exist.

Carbon nanotubes (CNTs) with good mechanical, unique electrical and magnetic properties, as well as extraordinary confinement effects have been widely used as support materials for catalysis [23-25]. Although the application of CNTs as supports for the preparation of solid chiral catalysts has not been fully investigated, CNTs have already demonstrated unique properties in asymmetric catalysis due to the elimination effects of the inner diffusion resistance of reactants and products, the $\pi-\pi$ interaction between CNTs and aromatic reactants, and the confinement effect on the reactants. For instance, enhanced enantioselectivity was observed for the asymmetric hydrogenation of $\alpha$-ketone esters using Pt confined in CNTs (cinchonidine as chiral modifier) [26]. Due to the lack of CNT functionalities, the immobilization of chiral molecular catalysts on CNTs remains a challenge.

Herein, we report the synthesis of polymer/CNTs (P/CNTs) composites by the one-pot radical polymerization of (1R,2R)- $N$-(4-vinyl-benzenesulfonyl)-1,2-diphenylethane-1,2-d iamine (VDPEN) and divinylbenzene (DVB) in the presence of
CNTs, for the asymmetric hydrogenation of quinolines. By combining CNTs with polymers, the facile chemical tailoring properties of polymers and the robustness and unique properties of CNTs can be exploited. Successive coordination with a $\mathrm{Ru}$ precursor and the anion exchange resulted in the formation of solid catalysts with VDPEN-RuOTf as active sites. In the asymmetric hydrogenation of 2-methylquinoline, the P/CNTs composites exhibited higher activity than those of corresponding pure polymers and polymer/C $(\mathrm{P} / \mathrm{C})$ composites, indicating the unique properties of CNTs as supports for asymmetric catalysis. The influence of the solvents on the catalytic performance and recycling stability of P-RuOTf/CNTs composites were fully investigated.

\section{Experimental}

\subsection{General}

All chemicals were used as received unless otherwise stated. Multiwalled carbon nanotubes (MCNTs) were purchased from Timesnano (Chengdu Organic Chemicals Co. Ltd, China). AIBN (2,2'-azobis(2-methylpropionitrile)) was recrystallized in ethanol before use. The compounds, 1-butyl-3-methylimidazolium hexafluorophosphate ([BMI][PF6]) and 1-butyl-3-methylimidazolium trifluoromethanesulfonate ([BMI] $\left[\mathrm{CF}_{3} \mathrm{SO}_{3}\right]$ ), were purchased from Aladdin Industrial Corporation and used after degassing at $120{ }^{\circ} \mathrm{C}$ for $3 \mathrm{~h}$. The ligand VDPEN was synthesized according to the method described in the literature [27].

$\mathrm{N} 2$ sorption isotherms at $-196^{\circ} \mathrm{C}$ were measured using a micromeritics ASAP 2020 volumetric adsorption analyzer. All the samples were outgassed at $120^{\circ} \mathrm{C}$ for $5 \mathrm{~h}$ before the measurements. The pore diameter was determined from the desorption branch by the BJH method. Elemental analysis was performed using a Carlo Erba 1106 Elemental Analyzer. FT-IR spectra were recorded on a Nicolet IS50 IR spectrometer. Transmission electron microscopy (TEM) was carried out on an FEI Tecnai G2 Spirit. The UV-Vis spectra of the filtrates were recorded on a SHIMADZU UV-Vis 2550 spectrophotometer. ${ }^{13} \mathrm{C}$ (100.5 MHz) cross-polarization magic-angle spinning (CP-MAS) solid-state NMR experiment was performed using Varian infinity plus 400 spectrometers referenced to tetramethylsilane. The content of Ru in the organic phase was determined by inductively coupled plasma atomic emission spectrometry (ICP-AES).

\subsection{Synthesis of the polymers with chiral ligand integrated into the network}

In a typical synthesis, $200 \mathrm{mg}$ of VDPEN, $600 \mathrm{mg}$ of DVB, and $80 \mathrm{mg}$ of AIBN were dissolved in $8 \mathrm{~mL}$ of DMF in a Schlenk tube, followed by heating at $80{ }^{\circ} \mathrm{C}$ for $20 \mathrm{~h}$ under $\mathrm{N}_{2}$ atmosphere. After cooling to room temperature, the solid product obtained by filtration was washed with dichloromethane severally and dried in a vacuum oven at $80^{\circ} \mathrm{C}$ for $5 \mathrm{~h}$. The polymer was denoted as P. The yield of the polymer was $~ 95 \%$, implying that the monomers were almost completely polymerized. 


\subsection{Synthesis of $P / C N T$ s and $P / C$ chiral composites}

The polymer/CNTs (P/CNTs) and polymer/activated carbon $(\mathrm{P} / \mathrm{C})$ were prepared by a method similar to that of $\mathrm{P}$. In a typical procedure, $200 \mathrm{mg}$ of VDPEN, $600 \mathrm{mg}$ of DVB, and 80 mg of AIBN were dissolved in $8 \mathrm{~mL}$ of DMF. The above solution was added slowly to $800 \mathrm{mg}$ of CNTs or activated carbon in a Schlenk tube. After sonication for $30 \mathrm{~min}$, the mixture was heated at $80{ }^{\circ} \mathrm{C}$ for $20 \mathrm{~h}$ under $\mathrm{N}_{2}$ atmosphere. After cooling to room temperature, the solid product obtained by filtration was washed with dichloromethane severally and dried in a vacuum oven at $80^{\circ} \mathrm{C}$, for $5 \mathrm{~h}$. Similar to that of the polymer, the yield of polymer-carbon composites was $\sim 95 \%$.

\subsection{Synthesis of chiral solid catalysts by Ru coordination and anion exchange}

In a typical procedure, $\left[\mathrm{Ru}(\mathrm{p} \text {-cymene }) \mathrm{Cl}_{2}\right]_{2}(5 \mathrm{mg} / \mathrm{mL})$ dissolved in a $10 \mathrm{~mL}$ solution of dichloromethane was added to $500 \mathrm{mg}$ of solid material (P, P/CNTs, or P/C). The mixture was stirred at room temperature for $2 \mathrm{~h}$. After filtration, the solid material was washed with copious amounts of dichloromethane to remove the uncoordinated Ru salts. Thereafter, the solid material was dried at room temperature under vacuum and denoted as $\mathrm{P}-\mathrm{RuCl}, \mathrm{P}-\mathrm{RuCl} / \mathrm{CNTs}$, or P-RuCl/C.

The P-RuCl, P-RuCl/CNTs, or P-RuCl/C was dispersed in $0.15 \mathrm{~mol} / \mathrm{L} \mathrm{KOH}$ solution $(10 \mathrm{~mL})$ and stirred vigorously at room temperature overnight. After filtration, the solid materials were washed with copious amounts of water and dried under vacuum at $50{ }^{\circ} \mathrm{C}$. Afterward, the solid materials were dispersed in $10 \mathrm{~mL}$ of a $\mathrm{CH}_{2} \mathrm{Cl}_{2}$ solution containing 1.2 equiv of TfOH for $2 \mathrm{~h}$ under $\mathrm{N}_{2}$ atmosphere. After filtration under $\mathrm{N}_{2}$, the solid catalysts were dried at room temperature under vacuum and denoted as P-RuOTf, P-RuOTf/CNTs, or P-RuOTf/C. The Ru contents in the filtration were quantified by UV-Vis spectroscopy.

\subsection{General procedure for the asymmetric hydrogenation of 2-methylquinoline}

As an example, 2-methylquinoline (100 $\mu \mathrm{L}, 0.74 \mathrm{mmol})$ and anhydrous methanol $(1.0 \mathrm{~mL})$ were added to a test tube containing the desired amount of solid catalysts $(7.4 \mu \mathrm{mol}$ of $\mathrm{Ru})$ in a glovebox. The test tube was transferred into a stainless steel autoclave and sealed. Before the reaction, the autoclave was purged three times with $\mathrm{H}_{2}$ and the pressure was adjusted to the desired value. After stirring at the desired temperature for desired time intervals, the autoclave was cooled to room temperature and $\mathrm{H}_{2}$ was released. The solid chiral catalyst was separated by centrifugation. The filtrate was directly analyzed by gas chromatography on an HP-5 capillary column (30 $\mathrm{m} \times 0.32 \mathrm{~mm} \times 0.25 \mathrm{~mm}$ ) to determine the conversion. After further purification of the filtrate using a silica gel column eluted with petroleum ether/dichloromethane $(1: 1, v / v)$, the enantiomeric excess value of the product was determined by HPLC on a chiral OJ-H column

For the recycling test in methanol, the solid catalyst was ob- tained by centrifugation, followed by washing 3 times in the glove box with $1 \mathrm{~mL}$ of anhydrous hexane. The solid catalyst was used directly for the next run. As for the recycling test in ILs, the products were extracted by $n$-hexane and the IL phase including the catalysts was used for the next cycle.

\section{Results and discussion}

\subsection{Synthesis and characterization}

VDPEN was cross-linked in the polymer network by the radical polymerization method with DVB and VDPEN as monomers (molar ratio of DVB to VDPEN was 9:0), and AIBN as an initiator, as illustrated in Scheme 1a. The polymerization in the presence of CNTs resulted in the formation of P/CNTs (Scheme 1b). The procedure was applied for the synthesis of $\mathrm{P} / \mathrm{C}$ with the addition of activated carbon (C). The catalysts, P-RuOTf, P-RuOTf/CNTs, and P-RuOTf/C, were synthesized by coordination with $\left[\mathrm{Ru}\left(\mathrm{p} \text {-cymene) } \mathrm{Cl}_{2}\right]_{2}\right.$, followed by anion exchange, as described in Scheme 1c. In the literature, Ru/Ts-DPEN could be facilely obtained by the reaction of $\mathrm{RuCl} / \mathrm{Ts}$-DPEN with AgOTf [28]. However, this procedure could not be used for preparing the solid catalyst due to the deposition of $\mathrm{AgCl}$. In this study, the $\mathrm{KOH}-\mathrm{TfOH}$ treatment procedure [29] was used for the generation of chiral solid catalysts with cationic active sites.

The textural properties of the $\mathrm{P}$ and $\mathrm{P} / \mathrm{C}$ composites were characterized by $\mathrm{N}_{2}$ sorption analysis (Fig. 1 and Table 1). $\mathrm{P}$ and $\mathrm{P} / \mathrm{C}$ showed type-IV $\mathrm{N}_{2}$ sorption isotherm patterns, indicating that they were mesoporous. The $\mathrm{N}_{2}$ isotherm of P/CNTs was in the board-line between microporosity and mesoporosity. P had a BET surface area of $474 \mathrm{~m}^{2} / \mathrm{g}$ with a pore volume of $0.39 \mathrm{~cm}^{3} / \mathrm{g}$ and a pore size of $4.0 \mathrm{~nm}$. P/C and P/CNTs had BET surface areas of 959 and $335 \mathrm{~m}^{2} / \mathrm{g}$, respectively. Compared with that of the parent material, the BET surface areas of $\mathrm{P} / \mathrm{CNTs}$ and $\mathrm{P} / \mathrm{C}$, respectively, increased and decreased. This is reasonable considering that the BET surface area of $\mathrm{P}$ is higher

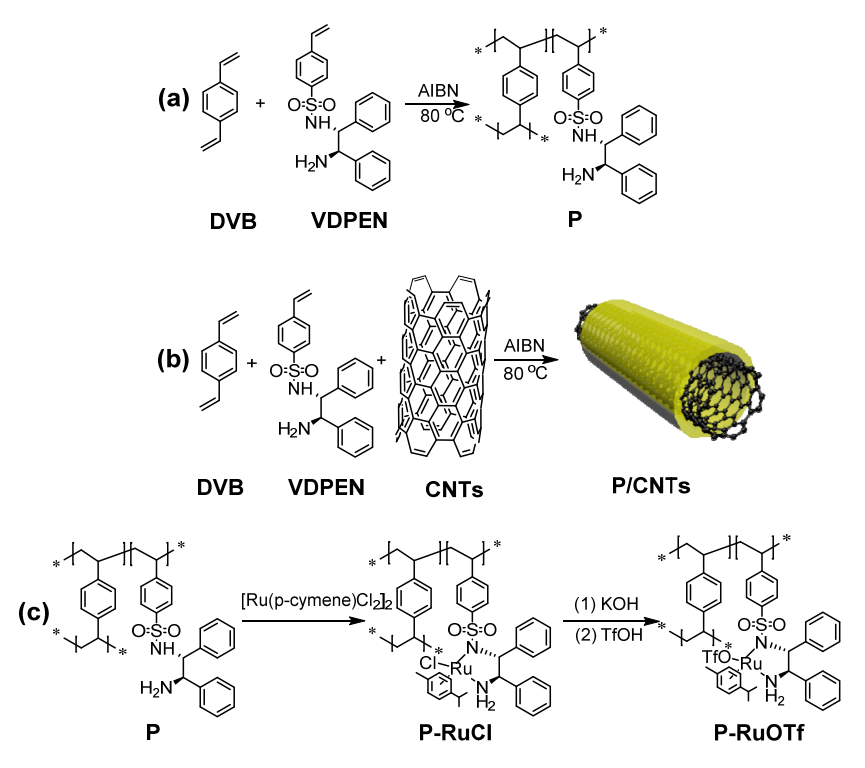

Scheme 1. Schematic illustration for the synthesis of (a) P, (b) P/CNTs, and (c) P-RuOTf. 

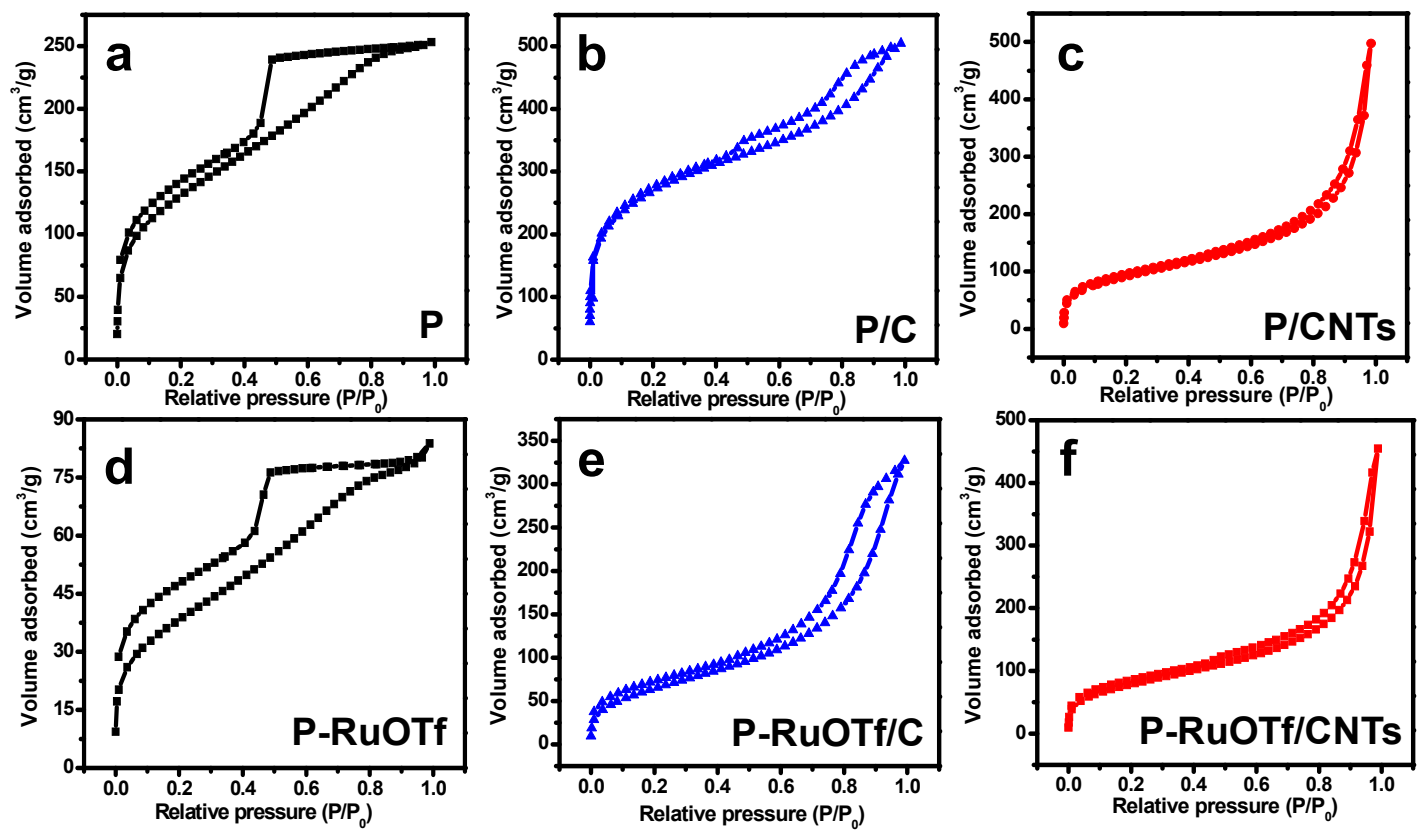

Fig. 1. $N_{2}$ sorption isotherms of $P$ and $P / C$ composites in the presence and absence of RuOTf complexes.

than that of CNTs, but lower than that of the activated carbon. The pore diameters of $\mathrm{P} / \mathrm{C}$ and $\mathrm{P} / \mathrm{CNT}$ s were identical to those of the corresponding supports, showing that the structures of the CNTs and activated carbon were robust enough during the polymerization process. The $\mathrm{P}$ and $\mathrm{P} / \mathrm{C}$ composites containing RuOTf exhibited $\mathrm{N}_{2}$ isotherm patterns that were almost identical to those of the parent materials. The BET surface area and pore volume of P-RuOTf were much lower than those of $\mathrm{P}$, possibly due to the pore occupation by RuOTf. However, the BET surface area and pore volume decreased slightly for P-RuOTf/CNTs and P-RuOTf/C compared with the trend observed with their parent materials, thereby showing the benefit of porous supports in preventing the sharp change in textural parameters after metal coordination.

The TEM and SEM images of $\mathrm{P}$ and $\mathrm{P} / \mathrm{C}$ composites and the corresponding solid catalysts are shown in Fig. 2. The TEM and SEM images showed that the polymer was composed of irregularly shaped large particles. P/CNTs exhibited almost the same tubular morphology as that of the CNTs, as indicated by the

Table 1

Chemical and physical parameters of $\mathrm{P}$ and $\mathrm{P} / \mathrm{C}$ composites in the presence and absence of RuOTf complexes.

\begin{tabular}{lccccc}
\hline Sample & $\begin{array}{c}\text { BET sur- } \\
\text { face area } \\
\left(\mathrm{m}^{2} / \mathrm{g}\right)\end{array}$ & $\begin{array}{c}\text { Pore } \\
\text { volume } \\
\left(\mathrm{cm}^{3} / \mathrm{g}\right)\end{array}$ & $\begin{array}{c}\text { Pore } \\
\text { size } \\
(\mathrm{nm})\end{array}$ & $\begin{array}{c}\mathrm{N} \\
(\mathrm{mmol} / \\
\mathrm{g})\end{array}$ & $\begin{array}{c}\mathrm{Ru} \\
(\mathrm{mmol} / \\
\mathrm{g})\end{array}$ \\
\hline $\mathrm{P}$ & 474 & 0.39 & 4.0 & 1.89 & - \\
$\mathrm{P} / \mathrm{CNTs}$ & 335 & 0.77 & $2.8,37.7$ & 0.89 & - \\
$\mathrm{P} / \mathrm{C}$ & 951 & 0.78 & 13.7 & 0.96 & - \\
P-RuOTf & 139 & 0.13 & 3.5 & 1.60 & 0.29 \\
P-RuOTf/CNTs & 291 & 0.70 & $2.7,37.0$ & 0.89 & 0.22 \\
P-RuOTf/C & 713 & 0.66 & 13.6 & 1.10 & 0.20 \\
CNTs & 110 & 0.63 & $3.0,37.0$ & - & - \\
$\mathrm{C}$ & 1483 & 0.84 & - & - & - \\
\hline
\end{tabular}

TEM images. Due to the contrast between polymer and CNTs, the polymers closely deposited on the CNTs could be clearly observed in the TEM image of P/CNTs. The SEM image of $\mathrm{P} / \mathrm{CNT}$ s showed the entangled CNTs and no large polymer particles could be observed, which further confirms the TEM result that CNTs and the polymer are in close contact, possibly due to the $\pi-\pi$ interactions between the CNTs and the polymer. P/C exhibits a similar morphology to $\mathrm{C}$, as indicated by the TEM images. This implies that the polymer was uniformly supported on activated carbon. No morphology changes could be observed after coordination with the Ru complex for all the solid materials; this confirms the high stabilities of the $\mathrm{P}$ and $\mathrm{P} / \mathrm{C}$ composites during the coordination and anion exchange process.

The chemical compositions of the $\mathrm{P}$ and composites were characterized by elemental analysis, FT-IR spectroscopy, and ${ }^{13} \mathrm{C}$ CP-MAS NMR (Table 1 and Fig. 3). N elemental analysis showed that the $\mathrm{N}$ contents in the $\mathrm{P}$ and $\mathrm{P} / \mathrm{C}$ composites were in the range of $0.9-1.9 \mathrm{mmol} / \mathrm{g}$. The $\mathrm{N}$ contents in the $\mathrm{P} / \mathrm{C}$ composites were almost half that in the pure polymer, which is consistent with the initial ratio of the monomers to carbon materials. The Ru contents in P-RuOTf and P-RuOTf/C were in the range of $0.29-0.20 \mathrm{mmol} / \mathrm{g}$, which are much lower than the ligand contents. This is because less than stoichiometric amounts of the Ru complex were used during the metal coordination process, due to the consideration that the existence of uncoordinated chiral ligands may prevent metal leaching during the catalytic process.

In the FT-IR spectrum of $\mathrm{P}$, the characteristic band of $\mathrm{C}-\mathrm{N}$ at $1096 \mathrm{~cm}^{-1}$ and the vibration bands of $\mathrm{O}=\mathrm{S}=0$ at 1162 and 1340 $\mathrm{cm}^{-1}$, demonstrate the successful cross-linking of the VDPEN ligand in the polymer framework $[27,30]$. The FT-IR spectra of $\mathrm{P} / \mathrm{CNTs}$ and $\mathrm{P} / \mathrm{C}$ were almost identical to that of $\mathrm{P}$, indicating 

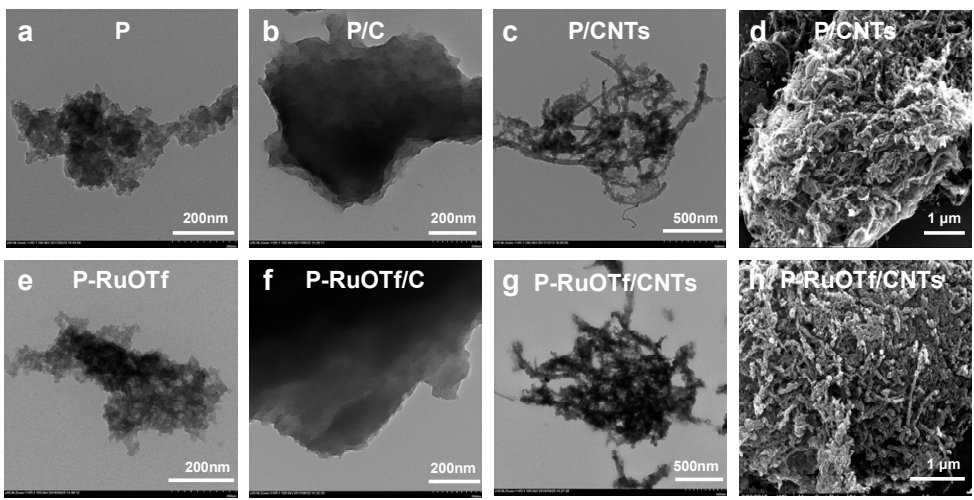

Fig. 2. TEM (a-c, e-g) and SEM $(d, h)$ images of $P$ and $P / C$ composites in the presence and absence of RuOTf complexes.
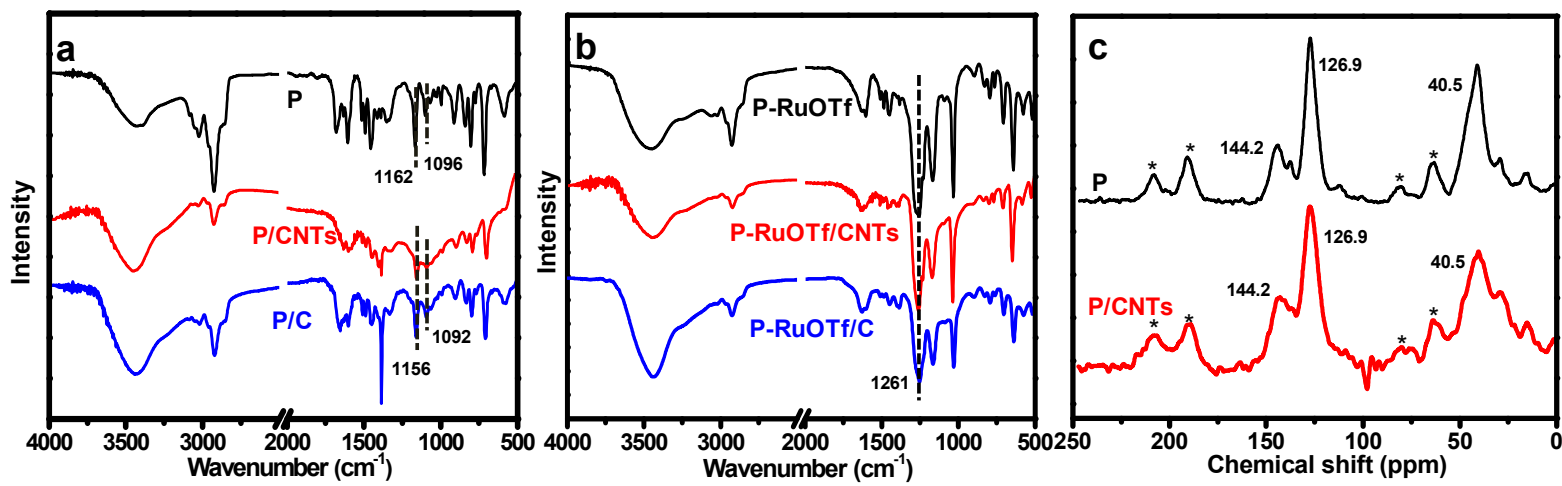

Fig. 3. FT-IR spectra of $\mathrm{P}$ and $\mathrm{P} / \mathrm{C}$ composites in the absence (a) and presence (b) of RuOTf. (c) ${ }^{13} \mathrm{C}$ CP-MAS NMR spectra of $\mathrm{P}$ and $\mathrm{P} / \mathrm{CNTs}$.

the successful deposition of the polymer on CNTs and activated carbon. Compared with the trend in the P spectrum, slight redshifts of the vibration peaks for C-N (from 1096 to $1092 \mathrm{~cm}^{-1}$ ) and $\mathrm{O}=\mathrm{S}=0$ (from 1162 to $1156 \mathrm{~cm}^{-1}$ ) were observed in the FT-IR spectrum of the $\mathrm{P} / \mathrm{C}$ composites, which is possibly due to the weak interactions between the polymer and supports. In the ${ }^{13} \mathrm{C}$ CP-MAS NMR spectra of P and P/CNTs, the chemical shifts at $\delta=144.2$ indicative of the aromatic ring, $\delta=126.9$ of $\mathrm{C}-\mathrm{H}$, and $\delta=40.5$ of $\mathrm{CH}_{2}$ could be clearly observed, which further confirmed the formation of polymers in the presence and absence of carbon materials.

In addition to the vibrations of $\mathrm{C}-\mathrm{N}$ and $\mathrm{O}=\mathrm{S}=\mathrm{O}$, a strong new band at $1261 \mathrm{~cm}^{-1}$ assigned to the vibration of the $\mathrm{C}-\mathrm{F}$ bond could be clearly observed in the FT-IR spectrum of P-RuOTf, accompanied with the distinct increase in the relative intensity of the $\mathrm{O}=\mathrm{S}=\mathrm{O}$ vibration. Similar phenomena were observed for P-RuOTf/CNTs and P-RuOTf/C. The results of the FT-IR spectra confirmed the successful formation of RuOTf active sites in $\mathrm{P}$ and $\mathrm{P} / \mathrm{C}$ composites.

\subsection{Asymmetric hydrogenation of 2-methylquinoline}

To evaluate the catalytic performance of solid chiral catalysts, the asymmetric hydrogenation of 2-methylquinoline was chosen as a model reaction, and the catalytic results are summarized in Table 2. All the solid chiral catalysts could catalyze the reaction to afford 1,2,3,4-tetrahydroquinoline with 90\%-91\% ee. Under similar reaction conditions, the homoge- neous catalyst, VDPEN-RuOTf, afforded $95 \%$ ee. The slightly decreased ee value of the solid chiral catalysts is possibly due to the variation in the chiral microenvironment of VDPEN-RuOTf in the solid catalysts. Under $40{ }^{\circ} \mathrm{C}$ and $5 \mathrm{MPa} \mathrm{H}_{2}$, the conversion of 2-methylquinoline increased in the order of P-RuOTf < P-RuOTf/C < P-RuOTf/CNTs. The TOF values followed the same trend. The TOF of P-RuOTf/CNTs was $27 \mathrm{~h}^{-1}$, which was three times that of P-RuOTf and 1.6 times that of P-RuOTf/C. The composites exhibited higher activities than P-RuOTf, thereby demonstrating the advantages of the composites in improving the catalytic activity. This is possibly due to their large BET surface areas and pore volumes, which may facilitate the high exposure of active sites. P-RuOTf/C, with a

\section{Table 2}

Catalytic performance of solid chiral catalysts in the asymmetric hydrogenation of 2-methylquinoline a.

\begin{tabular}{lcccccc}
\hline Catalyst & $\begin{array}{c}\text { Time } \\
(\mathrm{h})\end{array}$ & $\begin{array}{c}\text { Temp. } \\
\left({ }^{\circ} \mathrm{C}\right)\end{array}$ & $\begin{array}{c}\mathrm{H}_{2} \\
(\mathrm{MPa})\end{array}$ & $\begin{array}{c}\text { Conv. } \\
(\%)\end{array}$ & $\begin{array}{c}\text { ee } \\
(\%)\end{array}$ & $\begin{array}{c}\text { TOF b } \\
\left(\mathrm{h}^{-1}\right)\end{array}$ \\
\hline VDPEN-RuOTf & 4 & 40 & 5 & 99 & 95 & 211 \\
P-RuOTf & 4 & 40 & 5 & 29 & 90 & 7 \\
P-RuOTf/C & 4 & 40 & 5 & 72 & 90 & 17 \\
P-RuOTf/CNTs & 4 & 40 & 5 & 91 & 91 & 27 \\
P-RuOTf/CNTs & 2 & 60 & 5 & 98 & 90 & 44 \\
P-RuOTf/CNTs & 2 & 80 & 5 & 98 & 87 & 101 \\
P-RuOTf/CNTs & 4 & 40 & 2 & 75 & 91 & 19 \\
\hline
\end{tabular}

a Reaction conditions: 2-methylquinoline $(0.74 \mathrm{mmol}), \mathrm{S} / \mathrm{C}=100,500$ rpm, $1 \mathrm{~mL}$ methanol. ${ }^{\mathrm{b}}$ Turnover frequency was calculated with a conversion of $<30 \%$. 


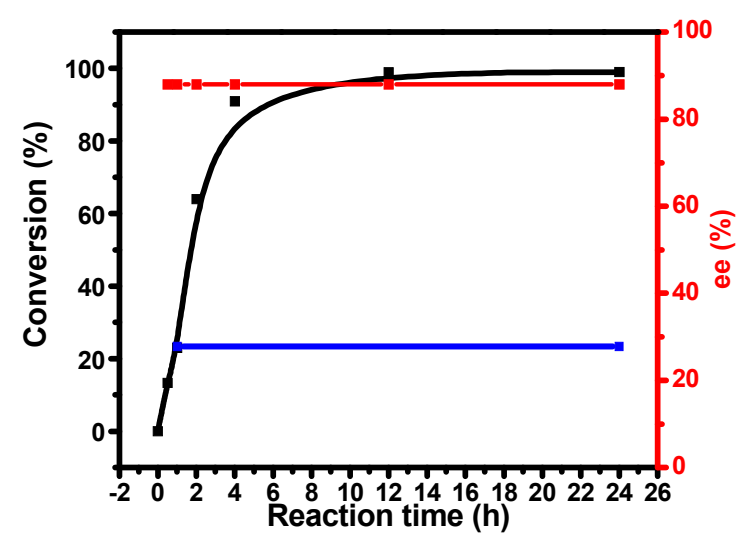

Fig. 4. Kinetic plots of the filtration experiment in the asymmetric hydrogenation of 2-methylquinoline over P-RuOTf/CNTs.

higher BET surface area than that of P-RuOTf/CNTs, exhibited lower activity, showing that other factors may also influence the catalytic performance of the solid catalysts in addition to the BET surface area. Compared with the external surface provided by activated carbon, CNTs with tubular morphologies may provide a larger outside surface area for dispersing the polymer to increase the exposure degree of the active sites. In fact, the polymer content of P-RuOTf/CNTs also significantly influences the catalytic performance. With a polymer content higher than $50 \mathrm{wt} \%$, a sharp decrease in both ee and conversion was observed, which is due to the phase separation, as indicated by the TEM image. Although P-RuOTf/CNTs exhibited a much higher activity than the other solid catalysts, its activity was still much lower than that of the homogeneous catalyst, which indicates that the porous structure of the solid chiral catalyst needs to be further optimized.

The filtration experiment was performed to test whether the asymmetric hydrogenation was catalyzed by the solid catalyst, using P-RuOTf/CNTs as the model (Fig. 4). The reaction went on for $1 \mathrm{~h}$, after which the solid catalyst was filtered off in the glovebox. The filtrate was recharged with 50 bar $\mathrm{H}_{2}$ and stirred in an autoclave at $40{ }^{\circ} \mathrm{C}$ for another $23 \mathrm{~h}$. No marked increase in the conversion could be observed, proving that the asymmetric hydrogenation reaction was catalyzed by the solid
Table 3

Recycling stabilities of P-RuOTf and P-RuOTf/CNTs with methanol as the solvent ${ }^{\mathrm{a}}$.

\begin{tabular}{lccc}
\hline Catalyst & Run time & Conversion (\%) & ee (\%) \\
\hline P-RuOTf & 1 & 29 & 91 \\
P-RuOTf/CNTs & 2 & 4 & - \\
& 1 & 90 & 91 \\
\hline
\end{tabular}

a Reaction conditions: 2-methylquinoline (0.74 mmol), $\mathrm{S} / \mathrm{C}=100,500$ rpm, $40^{\circ} \mathrm{C}, 5 \mathrm{MPa}, 4 \mathrm{~h}, 1 \mathrm{~mL}$ methanol.

catalyst.

P-RuOTf/CNTs was chosen as the model catalyst for studying the influence of reaction conditions on catalytic performance. The reactivity can be influenced by the reaction temperature and pressure. With the increase in temperature from 40 to $80{ }^{\circ} \mathrm{C}$, the TOF gradually increased to $44 \mathrm{~h}^{-1}$ at $60^{\circ} \mathrm{C}$ and then to $101 \mathrm{~h}^{-1}$ at $80^{\circ} \mathrm{C}$, while the ee gradually decreased from $91 \%$ to $87 \%$. The conversion decreased from $91 \%$ to $78 \%$ as the reaction pressure decreased from 5 to $2 \mathrm{MPa}$ in $4 \mathrm{~h}$. Consequently, the asymmetric hydrogenation reaction in the following discussion was performed at $5 \mathrm{MPa} \mathrm{H}_{2}$ and at $40{ }^{\circ} \mathrm{C}$ with methanol as solvent.

\subsection{Recycling stability of the solid chiral catalysts in the asymmetric hydrogenation of 2-methylquinoline}

One of the merits of heterogeneous asymmetric catalysis is that the catalysts can be recycled. Thus, the recycling stabilities of P-RuOTf and P-RuOTf/CNTs were firstly tested with methanol as the solvent (Table 3). Unexpectedly, both P-RuOTf and P-RuOTf/CNTs were almost inactive and could not be used for the second cycle. To understand the reason for the low recycling stabilities of the solid chiral catalysts, the reused catalysts were characterized by FT-IR spectroscopy (Fig. 5a). In the FT-IR spectrum of the reused P-RuOTf/CNTs, distinct reductions in the intensities of the characteristic peaks of $\mathrm{S}=0$ (1159 $\left.\mathrm{cm}^{-1}\right)$ and $\mathrm{C}-\mathrm{F}\left(1258 \mathrm{~cm}^{-1}\right)$ were observed. This indicates that the loss of $\mathrm{CF}_{3} \mathrm{SO}_{3}^{-}\left(\mathrm{TfO}^{-}\right)$functional groups may be the main reason for the low recycling stability of the solid chiral catalysts.
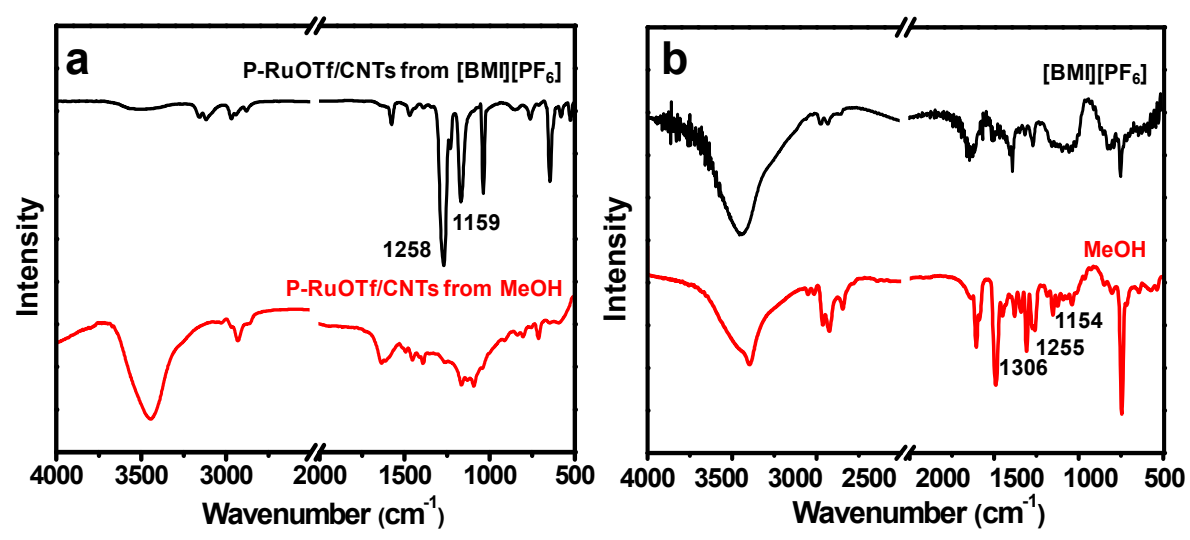

Fig. 5. FT-IR spectra of (a) reused P-RuOTf/CNTs from the reaction system with methanol and [BMI][PF6] as solvents and (b) the reaction filtrates with P-RuOTf/CNTs as the catalyst using methanol and [BMI][PF6] as solvents. 


\section{Table 4}

Catalytic performances of P-RuOTf/CNTs in the asymmetric hydrogenation of 2-methylquinoline with ILs as solvents a .

\begin{tabular}{|c|c|c|c|}
\hline Catalyst & Solvent & Conv. (\%) & ee $(\%)$ \\
\hline VDPEN-RuOTf & {$[\mathrm{BMI}]\left[\mathrm{PF}_{6}\right]$} & 99 & 98 \\
\hline VDPEN-RuOTf & {$[\mathrm{BMI}]\left[\mathrm{CF}_{3} \mathrm{SO}_{3}\right]$} & 99 & 92 \\
\hline P-RuOTf/CNTs & {$[\mathrm{BMI}]\left[\mathrm{PF}_{6}\right]$} & 98 & 80 \\
\hline P-RuOTf/CNTs & {$[\mathrm{BMI}]\left[\mathrm{CF}_{3} \mathrm{SO}_{3}\right]$} & 98 & 67 \\
\hline
\end{tabular}

a Reaction conditions: 2-methylquinoline (0.74 mmol), $\mathrm{S} / \mathrm{C}=50,1000$ rpm, $1 \mathrm{~mL}$ solvent, $60^{\circ} \mathrm{C}, 12 \mathrm{~h}$.

To further increase the recycling stability of the solid catalysts, the leaching of $\mathrm{TfO}^{-}$should be prevented. ILs, as a new class of solvents, can offer many superior properties over traditional organic solvents, such as extremely low vapor pressure, high chemical and thermal stability, high ionic conductivity, and confinement of ionic compounds [31-33]. Thus, [BMI][PF6] and $[\mathrm{BMI}]\left[\mathrm{CF}_{3} \mathrm{SO}_{3}\right]$ were chosen as solvents for the asymmetric hydrogenation of 2-methylquinoline (Table 4). As shown in Table 4, the homogeneous catalyst, VDPEN-RuOTf, could catalyze the reaction efficiently to obtain $99 \%$ conversion in the ILs. High ee values (as high as 98\%) were obtained with [BMI][PF6] as the solvent, even higher than that obtained with methanol as the solvent. The positive role of ILs in improving the ee value for the asymmetric hydrogenation of quinoline has been reported previously $[13,34]$. However, the ee value decreased sharply for P-RuOTf/CNTs in ILs compared with that in methanol. This is possibly due to the blocking of the porous channels in P-RuOTf/CNTs by viscous ILs.

With ILs as solvents, the recycling stability of P-RuOTf/CNTs was also investigated (Fig. 6a and 6b). Compared with that in methanol, the recycling stability of P-RuOTf/CNTs in ILs increased markedly. In both $[\mathrm{BMI}]\left[\mathrm{PF}_{6}\right]$ and $[\mathrm{BMI}]\left[\mathrm{CF}_{3} \mathrm{SO}_{3}\right]$, P-RuOTf/CNTs could be stably recycled at least five times without distinct losses in the conversion and ee values. This may be related to the confinement effect of ILs on $\mathrm{CF}_{3} \mathrm{SO}_{3}{ }^{-}$. To investigate whether the ILs could reduce the leaching of $\mathrm{TfO}^{-}$ from the solid catalyst, the reaction filtrates were also characterized using FT-IR spectroscopy (Fig. 5b). The filtrates after reaction were collected and diluted to the same volume as those using methanol as solvent. The peak intensities of $S=0$ and C-F, respectively, at 1154,1255 , and $1306 \mathrm{~cm}^{-1}$ were much lower in $[\mathrm{BMI}]\left[\mathrm{PF}_{6}\right]$ than in methanol, indicating that the loss of $\mathrm{TfO}^{-}$anion was reduced significantly. The FT-IR results of the reused catalysts discussed previously and the filtrates confirm that the leaching of $\mathrm{TfO}^{-}$anion should be the main reason for the low recycling stability of the solid catalysts in methanol.

After recycling, we characterized the reused catalyst by TEM and $\mathrm{N}_{2}$ adsorption experiment (Fig. $6 \mathrm{c}$ and $6 \mathrm{~d}$ ). The TEM image and the BET surface area of the reused catalyst are almost identical to those of the fresh one, thereby demonstrating the high morphology and structural stability of the composite material. In addition, we collected the filtrates after each cycle and tested the leached amount of Ru within five cycles by ICP. The total leached amount of Ru was about $0.8 \%$ for five cycles.

\section{Conclusions}

In this work, polymer-based solid chiral catalysts were prepared by a one-pot polymerization method for the asymmetric hydrogenation of 2-methylquinoline. The successive Ru coordination and anion exchange process resulted in the formation
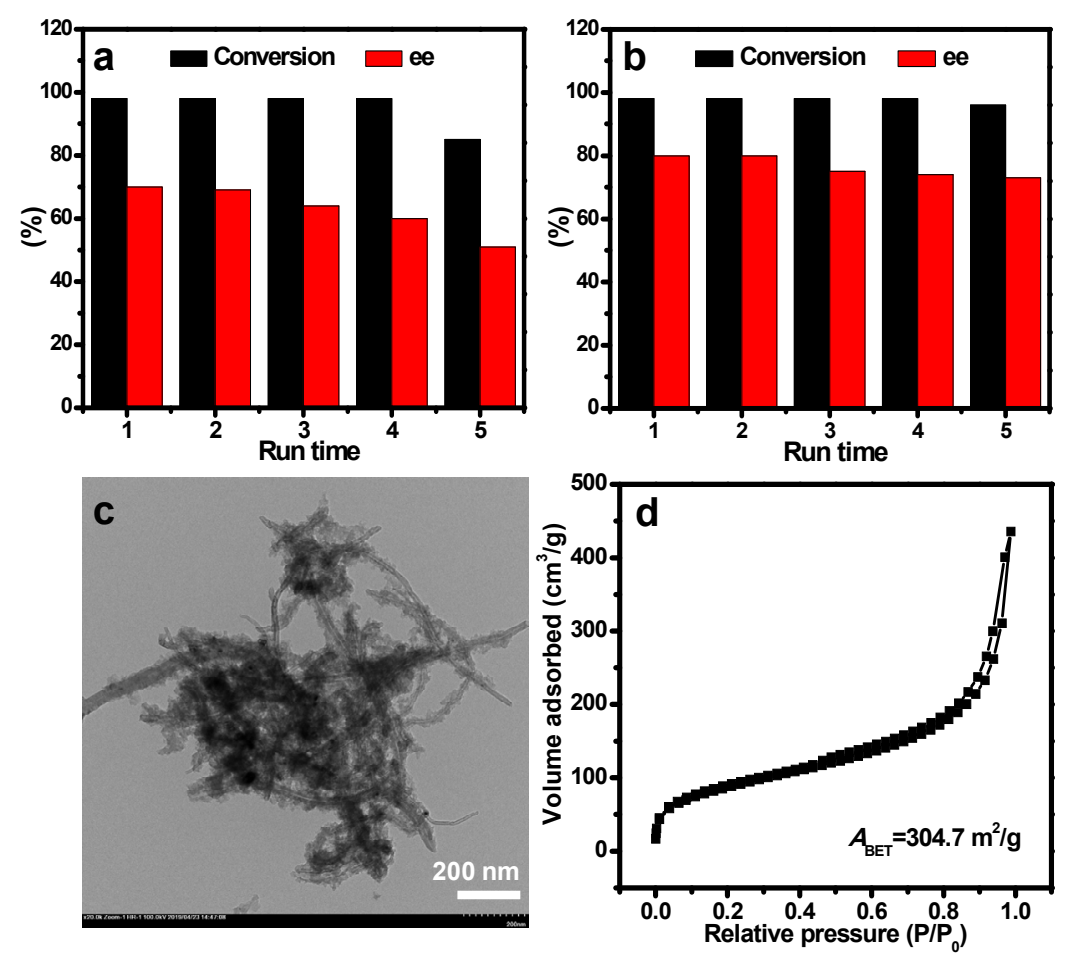

Fig. 6. Recycling test of P-RuOTf/CNTs in the asymmetric hydrogenation of 2-methylquinoline in (a) $\left[\mathrm{BMI}^{2}\left[\mathrm{CF}_{3} \mathrm{SO}_{3}\right]\right.$ and $(\mathrm{b})\left[\mathrm{BMI}_{[}\left[\mathrm{PF}_{6}\right]\right.$. The reaction conditions are the same as those in Table 4. (c) TEM image and (d) $\mathrm{N}_{2}$ sorption isotherm of the used catalyst after recycling. 
of solid catalysts with RuOTf as the active sites, as confirmed by FT-IR characterization. All the solid chiral catalysts could catalyze the asymmetric hydrogenation of 2-methylquinoline to afford 1,2,3,4-tetrahydroquinoline with $90 \%-91 \%$ ee. The catalytic activity of the solid chiral catalysts decreased in the order of P-RuOTf/CNTs > P-RuOTf/C > P-RuOTf. This suggests that the tubular morphologies of CNTs may facilitate the high exposure of the active sites. The loss of the $\mathrm{TfO}^{-}$group during the catalytic process directly led to the deactivation of the catalysts. This issue was partially remedied in ILs due to their confinement effect on ion compounds. This study may shed some light on the development of stable heterogeneous asymmetric catalysts for the asymmetric hydrogenation of quinoline and its derivatives.

\section{References}

[1] A. R. Katritzky, S. Rachwal, B. Rachwal, Tetrahedron, 1996, 52, 15031-15070.

[2] B. Nammalwar, R. A. Bunce, Molecules, 2014, 19, 204-232.

[3] V. Sridharan, P. A. Suryavanshi, J. C. Menendez, Chem. Rev., 2011, 111, 7157-7259.

[4] J. Balint, G. Egri, E. Fogassy, Z. Bocskei, K. Simon, A. Gajary, A. Friesz, Tetrahedron, 1999, 10, 1079-1087.

[5] M. Rueping, A. R. Antonchick, T. Theissmann, Angew. Chem. Int. Ed., 2006, 45, 3683-3686.

[6] Q. S. Guo, D. M. Du, J. Xu, Angew. Chem. Int. Ed., 2008, 47, 759-762.

[7] M. Rueping, T. Theissmann, Chem. Sci., 2010, 1, 473-476.

[8] W. B. Wang, S. M. Lu, P. Y. Yang, X. W. Han, Y. G. Zhou, J. Am. Chem. Soc., 2003, 125, 10536-10537.

[9] D. W. Wang, X. B. Wang, D. S. Wang, S. M. Lu, Y. G. Zhou, Y. X. Li, J.
Org. Chem., 2009, 74, 2780-2787.

[10] S. M. Lu, Y. Q. Wang, X. W. Han, Y. G. Zhou, Angew. Chem. Int. Ed., 2006, 45, 2260-2263.

[11] K. H. Lam, L. J. Xu, L. C. Feng, Q. H. Fan, F. L. Lam, W. H. Lo, A. S. C. Chan, Adv. Synth. Catal., 2005, 347, 1755-1758.

[12] Y. J. Zhao, Y. Q. Wang, Y. G. Zhou, Chin. J. Catal., 2005, 26, 737-739.

[13] H. F. Zhou, Z. W. Li, Z. J. Wang, T. L. Wang, L. J. Xu, Y. He, Q. H. Fan, J. Pan, L. Q. Gu, A. S. C. Chan, Angew. Chem. Int. Ed., 2008, 47, 8464-8467.

[14] B. Li, C. Xu, Y. M. He, G. J. Deng, Q. H. Fan, Chin. J. Chem., 2018, 36, 1169-1173.

[15] T. L. Wang, Y. Chen, G. H. Ouyang, Y. M. He, Z. Y. Li, Q. H. Fan, Chem.-Asian J., 2016, 11, 2773-2777.

[16] X. W. Wang, Z. Wang, K. L. Ding, in: C. Li, Y. Liu ed., Bridging Heterogeneous and Homogeneous Catalysis: Concepts, Strategies, and Applications, Wiley-VCH, Weinheim, 2014, 149-199.

[17] Q. H. Yang, D. F. Han, H. Q. Yang, C. Li, Chem.-Asian J., 2008, 3, 1214-1229.

[18] K. D. M. Harris, S. J. M. Thomas, ChemCatChem, 2009, 1, 223-231.

[19] D. F. Han, Q. H. Yang, C. Li, Chin. J. Catal., 2008, 29, 789-816.

[20] K. L. Ding, Z. Wang, X. W. Wang, Y. X. Liang, X. S. Wang, Chem.-Eur. J., 2006, 12, 5188-5197.

[21] T. Wang, Y. Lyu, K. Xiong, W. L. Wang, H. Zheng, Z. P. Zhan, Z. Jiang, Y. J. Ding, Chin. J. Catal., 2017, 38, 890-898.

[22] J. D. Hayler, D. K. Leahy, E. M. Simmons, Organometallics, 2019, 38, $36-46$.

[23] P. Serp, E. Castillejos, ChemCatChem, 2010, 2, 41-47.

[24] B. H. Wu, Y. J. Kuang, X. H. Zhang, J. H. Chen, Nano Today, 2011, 6, 75-90.

[25] Y. B. Yan, J. W. Miao, Z. H. Yang, F. X. Xiao, H. B. Yang, B. Liu, Y. H. Yang, Chem. Soc. Rev., 2015, 44, 3295-3346.

[26] Z. J. Chen, Z. H. Guan, M. R. Li, Q. H. Yang, C. Li, Angew. Chem. Int.

\section{Graphical Abstract}

Chin. J. Catal., 2019, 40: 1548-1556 doi: S1872-2067(19)63398-X

Synthesis of polymer/CNTs composites for the heterogeneous asymmetric hydrogenation of quinolines

Lin Tao, Chunzhi Li, Yiqi Ren, He Li, Jian Chen, Qihua Yang*

Dalian Institute of Chemical Physics, Chinese Academy of Sciences; University of Chinese Academy of Sciences

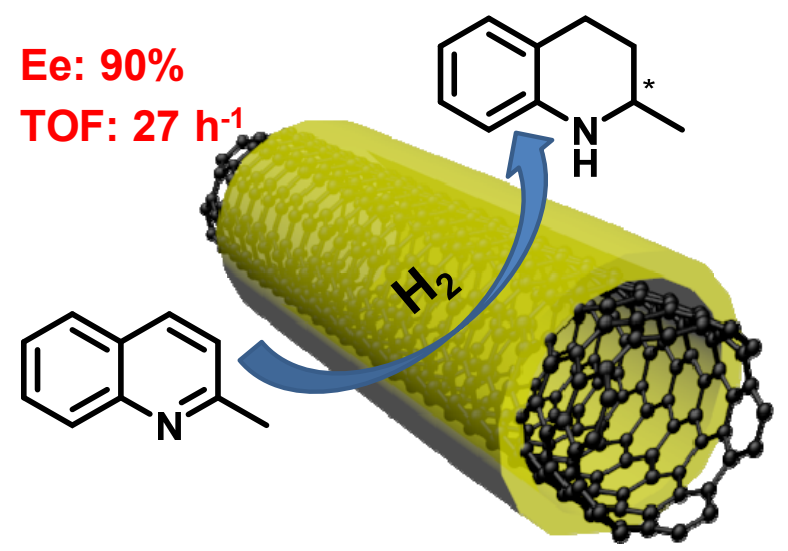

The polymer/CNTs composites with VDPEN-RuOTf as active sites could efficiently catalyze the asymmetric hydrogenation of 2-methylquinoline to afford 2-methyl-1,2,3,4-tetrahydroquinoline with $27 \mathrm{~h}^{-1} \mathrm{TOF}$ and $90 \%$ ee. 
Ed., 2011, 50, 4913-4917.

[27] Q. Sun, Y. Y. Jin, L. F. Zhu, L. Wang, X. J. Meng, F. S. Xiao, Nano Today, 2013, 8, 342-350.

[28] T. L. Wang, L. G. Zhuo, Z. W. Li, F. Chen, Z. Y. Ding, Y. M. He, Q. H. Fan, J. F. Xiang, Z. X. Yu, A. S. C. Chan, J. Am. Chem. Soc., 2011, 133, 9878-9891.

[29] S. Hashiguchi, A. Fujii, J. Takehara, T. Ikariya, R. Noyori, J. Am. Chem. Soc., 1995, 117, 7562-7563.

[30] X. M. Zhang, Y. P. Zhao, J. Peng, Q. H. Yang, Green Chem., 2015, 17,
1899-1906.

[31] H. Olivier-Bourbigou, L. Magna, D. Morvan, Appl. Catal. A, 2010, $373,1-56$.

[32] S. G. Zhang, J. H. Zhang, Y. Zhang, Y. Q. Deng, Chem. Rev., 2017, 117, 6755-6833.

[33] B. Karimi, M. Tavakolian, M. Akbari, F. Mansouri, ChemCatChem, 2018, 10, 3173-3205.

[34] Z. Y. Ding, T. L. Wang, Y. M. He, F. Chen, H. F. Zhou, Q. H. Fan, Q. X. Guo, A. S. C. Chan, Adv. Synth. Catal., 2013, 355, 3727-3735.

\title{
聚合物/碳纳米管复合材料的制备及催化喹啉手性氢化性能
}

\author{
陶 琳 ${ }^{\mathrm{a}, \mathrm{b}, \dagger}$ ，李纯志 ${ }^{\mathrm{a}, \mathrm{b}, \dagger}$ ，任亦起 ${ }^{\mathrm{a}, \mathrm{b}}$ ，李 贺 ${ }^{\mathrm{a}}$, 陈 建 ${ }^{\mathrm{a}, \mathrm{b}}$, 杨启华 ${ }^{*}$ \\ ${ }^{\mathrm{a}}$ 中国科学院大连化学物理研究所催化基础国家重点实验室, 辽宁大连 116023 \\ ${ }^{b}$ 中国科学院大学, 北京100049
}

\begin{abstract}
摘要: 光学活性的 $1,2,3,4$-四氢喹啉结构广泛存在于许多药物分子和天然生物碱中, 在生物医药和农药化学等方面具有十 分重要的应用. 发展光学活性的1,2,3,4-四氢哇啉及衍生物的手性催化合成方法具有重要的学术和工业应用价值. 2008年范 青华课题组成功将手性二胺-Ru的阳离子型催化剂用于喹啉及衍生物的手性氢化反应中,有效克服了有机膦配体在空气中 敏感的问题. 近十几年来, 喹啉及衍生物的手性氢化研究主要集中在均相催化体系. 然而, 均相催化体系面临着催化剂循环 利用的困难, 难以进行连续化工业生产. 此外, 手性药物合成中间体对纯度要求非常严格,残留贵金属催化剂的分离是均相 催化体系中的一大问题.

多相手性催化可有效解决上述问题,然而针对喹啉手性氢化的多相催化体系并不多见. 本文中,我们通过自由基聚合 的方法制备了骨架中富含手性二胺配体的多孔聚苯乙烯聚合物. 在此基础上, 通过在聚合过程中加入活性炭或碳纳米管, 制备了聚合物/活性炭和聚合物/碳纳米管复合材料. 在与 Ru金属配合物进行配位和阴离子交换后,制备了一系列含 VDPEN-RuOTf活性中心的手性固体催化剂. 通过红外光谱、 ${ }^{13} \mathrm{C}$ 核磁共振和元素分析等表征证实了聚合物及聚合物/碳材料 复合材料的成功制备, $\mathrm{N}_{2}$ 吸附表征表明聚合物/活性炭和聚合物/碳纳米管复合材料可以有效减少金属配位引起的聚合物材 料比表面积的降低. 固体催化剂红外光谱中出现了归属于 $\mathrm{C}-\mathrm{F}$ 键及 $\mathrm{S}=\mathrm{O}$ 键的特征振动峰, 表明固体催化剂中含有 VDPEN-RuOTf活性中心. 所有的手性固体催化剂在2-甲基喹啉的手性氢化反应中均能得到 $90 \%$ 的ee值. 研究表明聚合物/ 碳材料复合材料在相同反应条件下表现出比纯聚合物更好的反应活性,其中聚合物/碳管复合材料在所有手性固体催化剂 中表现出最高的反应活性, 这可能源于碳管独特的管状形貌. 以甲醇为溶剂, 手性固体催化剂在循环使用过程中催化活性 明显下降, 红外光谱表征显示阴离子 $\mathrm{TfO}^{-}$的流失是催化剂失活的主要原因. 以离子液为溶剂, 手性固体催化剂的循环稳定性 有所增加,这主要归因于离子液的离子限域作用抑制了 $\mathrm{TfO}^{-}$的流失.
\end{abstract}

关键词: 多相手性氢化; 喹啉; 二胺配体; 聚合物; 碳纳米管

收稿日期: 2019-04-04. 接受日期: 2019-05-01. 出版日期: 2019-10-05.

*通讯联系人. 电话: (0411)84379552; 传真: (0411)84694447; 电子信箱: yangqh@dicp.ac.cn

†共同第一作者.

基金来源：国家自然科学基金(21733009, 21621063); 中国科学院战略性先导科技专项(XDB17020200).

本文的电子版全文由Elsevier出版社在ScienceDirect上出版(http://www.sciencedirect.com/science/journal/18722067). 